\title{
Invasive occipital nerve stimulation for refractory chronic cluster headache: what evolution at long-term? Strengths and weaknesses of the method
}

\author{
Delphine Magis", Pascale Gérard and Jean Schoenen
}

\begin{abstract}
Background: Invasive Occipital Nerve Stimulation (iONS) is a costly technique which appears effective in drug-refractory chronic cluster headache ( $\mathrm{drCCH})$ management. Available data on long-term effectiveness and safety of iONS in this indication are scarce, though they could be useful to neurologists and patients in daily practice. The purpose of this short report is to discuss the very long-term outcome of a drCCH cohort, including adverse events.

Findings: Previously, favourable results were obtained with iONS in $15 \mathrm{drCCH}$ patients: $80 \%$ were significantly improved and $60 \%$ were pain free. We report here the very long-term follow-up (up to nine years) of 10 patients belonging to this cohort. Meanwhile 5 patients had to be definitively explanted because of device infection (3) or paresthesia intolerance (2). Four patients (40\%) evolved to an episodic form of $\mathrm{CH}$. Six remained chronic but their attack frequency was decreased by $70 \%$ on average. Intake of preventive drugs is still necessary in $80 \%$ of patients. All patients needed at least one battery replacement.

Conclusions: Up to nine years after implantation, iONS is still effective in most patients with drCCH. Concomitant preventive drugs remain often necessary. Forty percent of patients reverse to episodic $\mathrm{CH}$, possibly by natural history. iONS is not a benign procedure but device-related complications appear similar to those reported with other invasive neurostimulators.
\end{abstract}

Keywords: Cluster headache, Occipital nerve, Neurostimulation, Refractory, Adverse events

\section{Introduction}

Cluster headache $(\mathrm{CH})$, especially its chronic form (see [1] for definition), is among the most disabling primary headaches. A small percentage of chronic cluster headache patients $(\mathrm{CCH})$ do not respond to or do not tolerate existing preventive drugs and are considered as drugresistant $(\mathrm{drCCH},[2])$. In the last decades various nonpharmacological therapeutic strategies have been applied to relieve these patients, among them invasive Occipital Nerve Stimulation (iONS, [3-8]) that provided middleterm results similar to those of the more invasive and risky hypothalamic deep brain stimulation (hDBS, [9-11]). We published previously a prospective trial of iONS involving

\footnotetext{
* Correspondence: dmagis@chu.ulg.ac.be

Headache Research Unit, University Department of Neurology CHR,

Boulevard du 12ème de Ligne 1, 4000 Liège, Belgium
}

$15 \mathrm{drCCH}$ patients [5]. One patient had an immediate device infection and could not be evaluated. After 36 months on average, 11 of the 14 remaining patients $(\sim 0 \%)$ had an improvement of at least $90 \%$ in attack frequency, whereas $60 \%$ became pain-free for long time periods. Two patients did not respond or described mild improvement. Up to now, no sham-controlled study of iONS is available in $\mathrm{drCCH}$, but a large trial is ongoing [12].

Recently, Leone et al. [11] published the very longterm outcome (median 8.7 years) of $17 \mathrm{drCCH}$ patients treated with hDBS, and found out that $35 \%$ were still almost pain-free (i.e. less than one attack every three months) whereas another $35 \%$ reversed to an episodic cluster pattern. Unfortunately such data are not available for $\mathrm{drCCH}$ patients treated with iONS.
照 Springer

(c) 2016 Magis et al. Open Access This article is distributed under the terms of the Creative Commons Attribution 4.0 International License (http://creativecommons.org/licenses/by/4.0/), which permits unrestricted use, distribution, and reproduction in any medium, provided you give appropriate credit to the original author(s) and the source, provide a link to the Creative Commons license, and indicate if changes were made. 
Along the same line, we thus aimed to share some relevant information about the long-term clinical usefulness and especially the risks of this costly procedure, for both neurologists and patients, based on our experience of nearly nine years.

\section{Summary of methods}

The complete report of the methods and surgical procedure were described elsewhere [3,5]. Our cohort initially included $15 \mathrm{drCCH}$ patients with side-locked attacks from the start (Fig. 1, see flowchart, one woman, average age at implantation $47.6 \pm 9.6$ years, duration of the chronic phase $7 \pm 4.2$ years). In six of them, cluster headache had been chronic from the onset. All subjects gave written informed consent and the study was approved by the Local Ethics Committee, CHR Citadelle, Liège, Belgium. iONS (20052009) was performed only on the headache side, using a paddle-style stimulating lead with 4 distal electrodes (Medtronic 3587A Resume $\mathrm{II}^{\odot}$; Medtronic, Minneapolis, MN, USA) [3]. We used either Medtronic Itrel $3^{\circ}$ or Medtronic Synergy stimulators, and six patients received subsequently a rechargeable Medtronic Restore ${ }^{\bullet}$ when their first battery was empty. The stimulation parameters were adjusted to produce paraesthesia over the greater occipital nerve (GON) territory, covering the largest area of the $\mathrm{C} 2$ dermatome.

\section{Findings}

The outcome of the $15 \mathrm{drCCH}$ patients up to 8.6 years after implantation is summarized in Table 1. Five out of 15 patients had their stimulator removed (33\%). Two patients were explanted because they did not tolerate the paraesthesia (at 4 and 35 months, $14 \%$ ), although one of them was improved and evolved to an episodic $\mathrm{CH}$. This patient had been chronic from the onset, but remained episodic after iONS removal. Besides the immediate infection in one patient (see Introduction), three more patients were subsequently explanted because of a delayed infection (at 24, 38 and 53 months, $21 \%$, total rate of infections $27 \%$ ). In one of them the attack frequency increased dramatically afterwards, and he was thus reimplanted 10 months later.

The remaining 10 patients have a mean follow-up of 71 months (Table 1, range 54-103). CH attacks recurred in all patients who were pain-free at the previous middleterm follow-up. In four patients (40\%), attacks relapsed following an episodic pattern. The bouts responded to standard preventive therapies (suboccipital steroid infiltration, verapamil ...). The other six patients $(60 \%)$ became chronic again [1] with an mean attack frequency ranging from 3 to 30 per month, which represents a reduction of $70.8 \%$ on average, compared to baseline (Table 1). However, $8 / 10$ patients $(80 \%)$ still need preventive medications but only 5/10 (50 \%) are still stimulated (two are episodic and three chronic). Their main explanation to discontinue iONS was their improvement which persisted despite an interruption of the stimulation due to various reasons (cancer, empty battery...). Overall, compared to baseline period, 9/10 patients have at least a $50 \%$ decrease of attack frequency. Six are satisfied with the treatment. The need for repeated surgery is the main reason for patient's

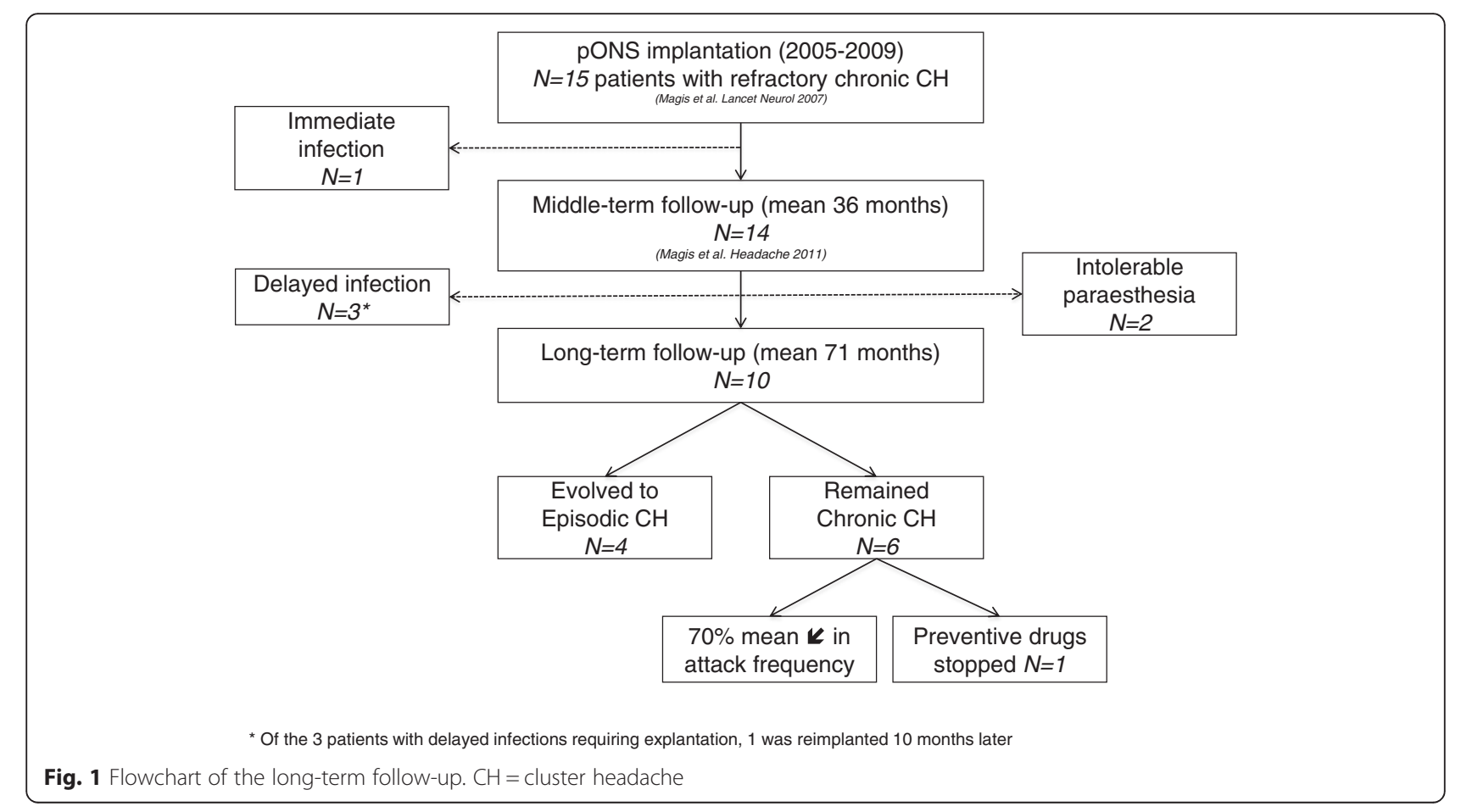


Table 1 Outcome of the $15 \mathrm{drCCH}$ patients treated with iONS. Patients in grey were explanted due to paraesthesia intolerance or infection

\begin{tabular}{|c|c|c|c|c|c|c|c|c|c|c|c|c|c|}
\hline Patients & Age & $\begin{array}{l}\mathrm{CH} \\
\text { natural } \\
\text { history }\end{array}$ & $\begin{array}{l}\mathrm{CCH} \\
\text { duration } \\
\text { (years) }\end{array}$ & $\begin{array}{l}\text { Time } \\
\text { under } \\
\text { ONS } \\
\text { (months) }\end{array}$ & $\begin{array}{l}\text { Attacks/day } \\
\text { before ONS } \\
\text { (mean) }\end{array}$ & $\begin{array}{l}\text { Attacks/day at } \\
\text { last follow-up } \\
\text { (mean) (Magis } \\
\text { Headache 2011) }\end{array}$ & $\begin{array}{l}\text { Attacks/day at } \\
\text { very long-term } \\
\text { follow-up } \\
\text { (mean) }\end{array}$ & $\begin{array}{l}\text { \% change } \\
\text { in attack } \\
\text { frequency }\end{array}$ & $\begin{array}{l}\text { Preventive therapy at } \\
\text { time of implantation }\end{array}$ & $\begin{array}{l}\text { Preventive therapy } \\
\text { at follow-up }\end{array}$ & Technical problems & iONS & Satisfaction \\
\hline 1 & 50 & $E$ & 9 & 4 & 0.29 & $\mathrm{~N} / \mathrm{A}$ & N/A & N/A & Verapamil & N/A & $\begin{array}{l}\text { Unbearable } \\
\text { paresthesias: explanted } \\
\text { after } 4 \text { months iONS }\end{array}$ & N/A & $\begin{array}{l}\text { Not satisfied } \\
\text { because of } \\
\text { paresthesias }\end{array}$ \\
\hline 2 & 53 & E & 3 & 103 & 4.7 & 0.43 & 0.33 & $-93.00 \%$ & Verapamil Melatonine & $\begin{array}{l}\text { Lithium carbonate } \\
\text { Verapamil }\end{array}$ & Empty battery: $\times 3$ & ON & Satisfied \\
\hline 3 & 51 & E & 7 & 102 & 3.84 & 0 & 0.1 & $-97.40 \%$ & $\begin{array}{l}\text { Lithium carbonate } \\
\text { Verapamil }\end{array}$ & None & $\begin{array}{l}\text { Empty battery: } \times 4 \\
\text { Lead migration: } \times 1\end{array}$ & ON & Very satisfied \\
\hline 4 & 37 & $E$ & 4 & 53 & 1.16 & 0.1 & 0.33 & $-71.55 \%$ & $\begin{array}{l}\text { Lithium carbonate } \\
\text { Verapamil }\end{array}$ & $\begin{array}{l}\text { Lithium carbonate } \\
\text { Verapamil }\end{array}$ & $\begin{array}{l}\text { Empty battery: } \times 2 \\
\text { Delayed infection: } \\
\text { explanted }\end{array}$ & N/A & $\begin{array}{l}\text { Very satisfied } \\
\text { then explanted }\end{array}$ \\
\hline 5 & 57 & E & 4 & 38 & 0.16 & 0 & N/A & N/A & Verapamil & N/A & $\begin{array}{l}\text { Delayed infection: } \\
\text { explanted }\end{array}$ & N/A & Not available \\
\hline 6 & 34 & C & 6 & 95 & 0.16 & 0 & Episodic & Episodic & $\begin{array}{l}\text { Lithium carbonate } \\
\text { Verapamil }\end{array}$ & $\begin{array}{l}\text { Verapamil Lithium } \\
\text { carbonate Topiramate }\end{array}$ & $\begin{array}{l}\text { Empty battery: } \\
\text { reluctant to } \\
\text { replacement }\end{array}$ & OFF & Satisfied \\
\hline 7 & 63 & $\mathrm{E}$ & 5 & 95 & 1.00 & 0 & 0.17 & $-83.00 \%$ & $\begin{array}{l}\text { Methysergide Lithium } \\
\text { carbonate }\end{array}$ & Lithium carbonate & Empty battery: $\times 3$ & ON & Satisfied \\
\hline 8 & 51 & $\mathrm{E}$ & 3 & 83 & 4.00 & 0 & 1 & $-75.00 \%$ & $\begin{array}{l}\text { Verapamil } \\
\text { Methylprednisolone }\end{array}$ & None & Empty battery: $\times 1$ & OFF & Not satisfied \\
\hline 9 & 53 & C & 29 & 35 & 1.5 & 0.16 & Episodic & Episodic & $\begin{array}{l}\text { Verapamil Lithium } \\
\text { carbonate Methysergide }\end{array}$ & $\begin{array}{l}\text { During bouts: GON } \\
\text { injection, verapamil, } \\
\text { lithium carbonate }\end{array}$ & $\begin{array}{l}\text { Unbearable } \\
\text { paresthasias: explanted }\end{array}$ & N/A & $\begin{array}{l}\text { Not satisfied } \\
\text { because of } \\
\text { paresthesias }\end{array}$ \\
\hline 10 & 33 & E & 5 & 68 & 2.00 & 0 & Episodic & Episodic & Verapamil & Verapamil Gabapentine & Empty battery: $\times 1$ & ON & Satisfied \\
\hline 11 & 46 & C & 2 & 64 & 0.57 & 0.5 & 0.54 & $-5.26 \%$ & $\begin{array}{l}\text { Verapamil Lithium } \\
\text { carbonate Gabapentine } \\
\text { Escitalopram }\end{array}$ & Verapamil Gabapentine & $\begin{array}{l}\text { Delayed device } \\
\text { infection: explanted } \\
\text { and reimplanted }\end{array}$ & ON & $\begin{array}{l}\text { Moderately } \\
\text { satisfied }\end{array}$ \\
\hline 12 & 34 & E & 8 & na & na & na & N/A & N/A & Methylprednisolone & N/A & $\begin{array}{l}\text { Immediate device } \\
\text { infection: explanted }\end{array}$ & N/A & N/A \\
\hline 13 & 67 & C & 5 & 58 & 3.5 & 0 & 1 & $-71.00 \%$ & $\begin{array}{l}\text { Lithium carbonate } \\
\text { Verapamil }\end{array}$ & $\begin{array}{l}\text { Lithium carbonate } \\
\text { Verapamil }\end{array}$ & Empty battery: $\times 1$ & OFF & Not satisfied \\
\hline 14 & 55 & C & 2 & 57 & 5.5 & 0 & Episodic & Episodic & $\begin{array}{l}\text { Methylprednisolone } \\
\text { Methysergide } \\
\text { Clomipramine }\end{array}$ & GON injection Verapamil & Empty battery: $\times 1$ & OFF & Not satisfied \\
\hline 15 & 30 & C & 14 & 54 & 3.00 & 0 & Episodic & Episodic & $\begin{array}{l}\text { Methysergide } \\
\text { Topiramate Verapamil }\end{array}$ & $\begin{array}{l}\text { GON injection Verapamil } \\
\text { Lithium carbonate }\end{array}$ & $\begin{array}{l}\text { Empty battery: } \times 1 \\
\text { Lead externalization }\end{array}$ & ON & Not satisfied \\
\hline
\end{tabular}

E evolved from an episodic to a chronic pattern, $C$ chronic since the onset, N/A not applicable 
dissatisfaction. Hence, patients stimulated at long-term had to undergo at least one additional surgery for battery replacement (up to four/patient). Two patients also needed surgery for lead migration (2/10: $20 \%)$. Some transient attack side-shifts (a single bout or isolated attacks) had been observed previously in nearly $30 \%$ of patients, but were not reported during the subsequent follow-up.

\section{Discussion}

Our data confirms that iONS is able to provide a longlasting relief in a majority of $\mathrm{drCCH}$ patients nearly 10 years after implantation.

All patients stimulated at long-term underwent at least one additional surgery for battery replacement, but the stimulators implanted initially had a limited lifetime and were expected to deplete after a time period depending on the stimulation intensity. Thus, a rechargeable device was placed subsequently to ensure a longer-lasting stimulation. Fifty-three percent of patients developed iONS-related complications, like immediate or delayed infections which finally required explantation of nearly $30 \%$ of patients. Besides the small size of our sample which could have biased the results, this high number of adverse events can be explained by several factors. First, the duration of our follow-up period is exceptionally long. The cumulated rate of adverse events probably increased with time and surgeries (especially repeated device replacements). Second, few similar safety data are available in the literature. A high complication rate was reported in chronic migraine patients treated with iONS [13]. In a cohort of 157 patients, after 1 year follow-up only, the authors recorded 183 device/ procedure-related adverse events, among which $8.6 \%$ required hospitalisation. Overall $32.5 \%$ of patients needed additional surgery; $16.6 \%$ had lead migration, $6.4 \%$ infection, $4.5 \%$ skin erosion and $18 \%$ local pain or numbness. Besides the rare but possibly fatal risk of intracerebral haemorrhage, hypothalamic deep brain stimulation (hDBS), has similar long-term complications such as infections (5/18, 1 immediate, $28 \%)$, electrode migration (2/17, $12 \%)$, or need for battery replacement (6/17, $35 \%)$ [11]. Larger long-term data are available for invasive vagus nerve stimulation in intractable epilepsy, and authors report side effects in $50 \%$ of patients, with surgical complications in $21 \%$ [14].

Our clinical data support that iONS is no more than a symptomatic therapy, as suggested before by other clinical [3] and neuroradiological [15] observations. iONS likely induces slow neuroplastic changes within nonspecific pain-control systems [3], which explains its beneficial effects in various headache types. The evolution of our patients was characterized by a sustained pain relief, even in some patients who had discontinued iONS (see Findings section). Forty patients became episodic and $60 \%$ stayed chronic, but many still needed a concomitant drug prophylaxis. With hDBS, after a similar follow-up time, $35 \%$ of $\mathrm{drCCH}$ patients remained 'almost' pain-free [11], but the chronic phase duration, which could mirror the disease severity, was on average twice longer in our population (seven years vs. three years for hDBS). However, comparing the outcomes of both techniques is challenging due to the small size of the series [11]. Interestingly, three patients who had been chronic from $\mathrm{CH}$ onset developed an episodic form after an initial pain-free period under iONS. A similar evolution from a pain-free state to an episodic form of $\mathrm{CH}$ has been described under hDBS in $35 \%$ of patients $(6 / 17)$ [11], however they were still stimulated; whereas the stimulator was turned off in the half of our population. Leone et al. suggested that hDBS might have changed the course of the illness by acting on circuits involved in disease chronification [11]. We have reported before that iONS applied during several months modulated central areas involved in non-specific pain control but did not modify the hypothalamic hypermetabolism found in $\mathrm{CH}$ [15]. It is also known that about $32 \%$ of "primary" $\mathrm{CCH}$ patients can spontaneously evolve to a "secondary" episodic type [16]. Thus, the emergence of an episodic pattern after iONS could either be due to the natural course of the disease, or be favoured by iONS.

In this trial, iONS had been performed unilaterally (headache side), in patients with strictly side-locked attacks. We previously observed a headache side shift in 4 patients $[3,5]$, but the latter was transient and fortunately did not recur at long-term. To avoid a possible attack side shift associated with chronification a bilateral stimulation is now proposed in $\mathrm{drCCH}$ patients.

\section{Conclusion}

Available open studies using iONS as add-on therapy have provided encouraging results in $\mathrm{drCCH}$, and iONS is now recommended before considering the more risky hDBS [17]. The very long-term evolution of patients treated with this technique is unknown.though, but this missing information is important for both neurologists and patients when considering invasive neurostimulation. Based on a 9-year experience, our data show that iONS remains very effective in patients who had initially benefitted from the procedure. That iONS did not prevent any relapse confirms its purely symptomatic effect on paincontrolling centres. Over time $40 \%$ of patients reversed to an episodic pattern of $\mathrm{CH}$, perhaps by natural history. This proportion is actually similar to the rate found in medically-treated $\mathrm{CCH}$ patients [15], but the cohort studied here involved a subset of the most severely ill $\mathrm{drCCH}$ sufferers, some of them being in chronic phase for several dozens of years. The treatment could thus have modified the course of the disease through a slow neuromodulation phenomenon. 
Like other invasive neurostimulation techniques, iONS is not harmless and its use in $\mathrm{drCCH}$ patients should be considered carefully. Adverse events occurred in about $50 \%$ of the subjects over time, but does not seem to deviate significantly from cumulated rates described with other techniques at very long-term (hDBS and VNS). The refinement of surgical techniques and devices will probably reduce the hardware-related complications. It is also strongly suggested to refer patients to trained surgeons who are familiar with iONS placement [13]. Patients must be aware that additional surgeries may be needed to replace empty batteries (also rechargeable batteries have a limited lifetime).

At present, because less risky than hDBS, iONS is recommended to the most disabled $\mathrm{drCCH}$ patients when invasive neurostimulation is considered. If available, non-invasive neurostimulation devices like vagus nerve [18] or transcranial direct current stimulators should be tried before performing invasive procedures (see European Headache Federation Statement [17]).

\section{Abbreviations}

$\mathrm{CH}$ : cluster headache; drCCH: drug-resistant chronic cluster headache; GON: great occipital nerve; hDBS: hypothalamic deep brain stimulation; iONS: invasive occipital nerve stimulation.

\section{Competing interests}

DM and JS are members of Medtronic ${ }^{\oplus}$ Advisory Board.

\section{Authors' contributions}

DM followed the patients, analyzed the data and wrote the manuscript. PG contacted patients and collected the clinical data. JS followed the patients. The manuscript was sent to all authors for approval. All authors read and approved the final manuscript.

\section{Declarations}

The devices used in this study were generously provided by Medtronic ${ }^{\oplus}$. Data analysis and patient follow-up were under the responsibility of the authors.

Received: 6 November 2015 Accepted: 2 February 2016

Published online: 16 February 2016

\section{References}

1. The International Classification of Headache Disorders, 3rd edition (beta version). (2013) Cephalalgia; 33(9):629-808.

2. Mitsikostas DD, Edvinsson L, Jensen RH et al (2013) Refractory chronic cluster headache: a consensus statement on clinical definition from the European Headache Federation. J Headache Pain 15:79

3. Magis D, Allena M, Bolla M, De Pasqua V, Remacle JM, Schoenen J (2007) Occipital nerve stimulation for drug-resistant chronic cluster headache: a prospective pilot study. Lancet Neurol 6(4):314-321

4. Burns B, Watkins L, Goadsby PJ (2009) Treatment of intractable chronic cluster headache by occipital nerve stimulation in 14 patients. Neurology 72(4):341-345

5. Magis D, Gerardy PY, Remacle JM, Schoenen J (2011) Sustained effectiveness of occipital nerve stimulation in drug-resistant chronic cluster headache. Headache 51(8):1191-1201

6. Fontaine D, Christophe Sol J, Raoul S et al (2011) Treatment of refractory chronic cluster headache by chronic occipital nerve stimulation. Cephalalgia 31(10):1101-1105

7. Strand NH, Trentman TL, Vargas BB, Dodick DW (2011) Occipital nerve stimulation with the bion (R) microstimulator for the treatment of medically refractory chronic cluster headache. Pain Phys 14(5):435-440
8. Mueller OM, Gaul C, Katsarava Z, Diener HC, Sure U, Gasser T (2011) Occipital nerve stimulation for the treatment of chronic cluster headachelessons learned from 18 months experience. Central European Neurosurgery 72(2):84-89

9. Schoenen J, Di Clemente L, Vandenheede M et al (2005) Hypothalamic stimulation in chronic cluster headache: a pilot study of efficacy and mode of action. Brain 128(Pt 4):940-947

10. Fontaine D, Lazorthes $Y$, Mertens $P$ et al (2010) Safety and efficacy of deep brain stimulation in refractory cluster headache: a randomized placebocontrolled double-blind trial followed by a 1-year open extension. J Headache Pain 11(1):23-31

11. Leone M, Franzini A, Proietti Cecchini A, Bussone G (2013) Success, failure, and putative mechanisms in hypothalamic stimulation for drug-resistant chronic cluster headache. Pain 154(1):89-94

12. Wilbrink LA, Teernstra OP, Haan J et al (2013) Occipital nerve stimulation in medically intractable, chronic cluster headache. The ICON study: rationale and protocol of a randomised trial. Cephalalgia 33(15):1238-1247

13. Sharan A; Huh B, Narouze S, Trentman T et al. (2014) Analysis of Adverse Events in the Management of Chronic Migraine by Peripheral Nerve Stimulation. Neuromodulation Oct 14. doi:10.1111/ner.12243. [Epub ahead of print]

14. Ching J, Khan S, White P et al (2013) Long-term effectiveness and tolerability of vagal nerve stimulation in adults with intractable epilepsy: a retrospective analysis of 100 patients. Br J Neurosurg 27(2):228-234

15. Magis D, Bruno MA, Fumal A et al (2011) Central modulation in cluster headache patients treated with occipital nerve stimulation: an FDG-PET study. BMC Neurol 11(1):25

16. Manzoni GC, Micieli G, Granella F, Tassorelli C, Zanferrari C, Cavallini A (1991) Cluster headache-course over ten years in 189 patients. Cephalalgia 11(4):169-174

17. Martelletti $P$, Jensen RH, Antal A et al (2013) European Headache Federation. Neuromodulation of chronic headaches: position statement from the European Headache Federation. J Headache Pain 14:86

18. Gaul C, Diener HC, Silver N, Magis D, Reuter U, Andersson A, Liebler EJ, Straube A; PREVA Study Group (2015) Non-invasive vagus nerve stimulation for PREVention and Acute treatment of chronic cluster headache (PREVA): A randomised controlled study. Cephalalgia. Sep 21. [Epub ahead of print]

\section{Submit your manuscript to a SpringerOpen ${ }^{\circ}$ journal and benefit from:}

- Convenient online submission

- Rigorous peer review

- Immediate publication on acceptance

- Open access: articles freely available online

- High visibility within the field

- Retaining the copyright to your article

Submit your next manuscript at $\boldsymbol{s p r i n g e r o p e n . c o m ~}$ 